\title{
Toxoplasma gondii: Usefulness of ROP1 Recombinant Antigen in an Immunoglobulin G Avidity Assay for Diagnosis of Acute Toxoplasmosis in Humans
}

\author{
LUCYNA HOLEC-GAূSIOR ${ }^{1}$, DOROTA DRAPAŁA ${ }^{1}$, DARIUSZ LAUTENBACH ${ }^{2}$ and JÓZEF KUR ${ }^{1 *}$ \\ ${ }^{1}$ Gdańsk University of Technology, Chemical Faculty, Department of Microbiology, Gdańsk, POLAND \\ ${ }^{2}$ Medical University of Gdańsk, Department of Obsterics, Gdańsk, POLAND
}

Received 29 July 2010, revised 8 September 2010, accepted 10 September 2010

\begin{abstract}
The results present in this study suggest that the Toxoplasma gondii recombinant ROP1 antigen in an IgG avidity test can be useful for detection of acute stage of infection. Specific antibodies of low avidity were detected in most of the sera from individuals with acute toxoplasmosis, while the absence or specific antibodies of high avidity were detected in sera from patients with chronic infection.
\end{abstract}

Ke y w ords: Toxoplasma gondii, ELISA, recombinant antigen, rhoptry protein 1, serology

Toxoplasma gondii is an obligate intracellular parasite that infects many warm-blooded animals. Although, human toxoplasmosis is generally asymptomatic, a serious disease can occur in the case of a congenital infection and immunocompromised individuals such as AIDS patients and transplant recipients (McAuley et al., 1994; Sàfadi et al., 2003). For that reason, it is crucial to estimate the time of infection in pregnant women. Detection of specific IgM and IgG are important but inadequate steps in diagnosis of acute toxoplasmosis (Bertozzi et al., 1999; Bessieres et al., 1992; Brooks et al., 1987; Iqbal and Khalid, 2007; Liesenfeld et al., 1997). The determination of the avidity index of $\operatorname{IgG}$ antibodies is considered very important in the diagnosis of an acute infection $v s$ a chronic infection (Jenum et al., 1997; Lappalainen et al., 1993; Liesenfeld et al., 2001; Montoya et al., 2002). In most cases, the currently available commercial tests are based on antigens obtained from a whole tachyzoites of Toxoplasma (TLA). The methods of producing tachyzoites as well as antigen(s) may vary significantly between laboratories and this means that the test is difficult to standardize. Furthermore, it was confirmed that low IgG avidity may be detected for a long time after infection (Ashburn et al., 1998; Villavedra et al., 1999). That is why recombinant antigens are considered to replace the antigen obtained from lysed whole parasites. In this case the antigen composition of the test is precisely known and the method can be easily standardized. Several recent studies have reported the use of recombinant antigens (Beghetto et al., 2003; Marcolino et al., 2000) or mixture of proteins (Pietkiewicz et al., 2005) in determination of IgG avidity.

The aim of this study was to estimate the diagnostic value of r-ROP1 in IgG ELISA avidity for serodiagnosis of $T$. gondii infection in humans.

A total of 172 serum samples received from a routine toxoplasmosis screening were analyzed and divided into four groups according to the results obtained with the VIDAS Toxo-IgG, VIDAS Toxo-IgG avidity, and VIDAS Toxo-IgM commercial tests (bioMérieux, France): group I - 34 sera from patients suspected of an acute toxoplasmosis (positive IgM, positive $\operatorname{IgG}$ with low or borderline avidity); group II - 16 sera from patients with postacute toxoplasmosis (negative IgM, positive IgG with low or borderline avidity); group III - 92 sera from patients with chronic toxoplasmosis (negative IgM, positive IgG with high avidity); IV group - 30 sera from seronegative individuals. Furthermore, we analyzed the avidity maturation of specific antibodies in serum samples received from

* Corresponding author: J. Kur, Gdańsk University of Technology, Department of Microbiology, Narutowicza 11/12, 80-233 Gdańsk, Poland; phone: (+48) 58 3472302; fax: (+48) 58 3471822; e-mail: kur@pg.gda.pl 
seven pregnant women classified as patients with acute or postacute phase of toxoplasmosis.

In this study, we used in-house IgG ELISA test with r-ROP1 expressed and purified as described in our previous paper (Holec-Gąsior et al., 2009). Each serum sample was used in increasing serial dilutions $(1: 100-1: 800)$ in separate plates coated with r-ROP1 and there were two different IgG ELISA procedures: normal and avidity ELISA washed with urea solution (PBS, $0.1 \%$ Triton $\mathrm{X}-100$ with $6 \mathrm{M}$ urea) three times for $10 \mathrm{~min}$. All groups of human sera were examined by IgG ELISA and three groups (I-III) by IgG ELISA avidity test. Group IV was tested in order to calculate the cutoff which was set as the mean value of the negative serum samples plus two standard deviations.

The results were shown as avidity indexes (AIs) which were calculated as the ratio between optical density for the sample washed with urea solution and optical density for the sample washed with washing buffer (for the dilution which gave OD near 1.0). AI below 0.3 was considered as low avidity, 0.3-0.4 as borderline avidity and values above 0.4 as high avidity. This division was established on the basis of results obtain by Paul (1999) and applied by Pietkiewicz et al. (2007).

None of the negative serum samples reacted above cutoff, resulting in a specificity of $100 \%$ for ELISAs
(Fig. 1). The sensitivity of IgG ELISA for r-ROP1 calculated for three groups of positive sera was at $43 \%$. However, reactivity was different in each group (Fig. 1). Examination of group I sera showed that 29 out of $34(85 \%)$ reacted with rROP1 and in 26 out of 29 cases $(90 \%)$ reacted at low or borderline avidity. Only three sera $(10 \%)$ from this group reacted at high avidity. In group II, 6 serum samples out of $16(37,5 \%)$ had specific IgG antibodies against r-ROP1 and 4 of them reacted at high avidity, 2 at low or borderline avidity. Only 23 out of 92 sera (25\%) from patients with chronic toxoplasmosis (group III) reacted with r-ROP1 and 22 cases (96\%) were with high avidity. Only one serum sample from this group had low avidity (Fig. 2).

In this study we also demonstrated a comparison of avidity maturation of specific IgG antibodies against r-ROP1 and lysed, whole-cell antigen (TLA) in sera from seven pregnant women suspected of acute or postacute toxoplasmosis. Our results showed an increase in time of the avidity indexes (AI) in the $\operatorname{IgG}$ ELISA with TLA for all individuals tested (Table I). In the IgG ELISA with r-ROP1 antigen the increase of the avidity indexes was also observed for five individuals, however, there was no reactivity with specific IgG for three patients' serum samples (4 sera) obtained after 2, 8, 10 or 16 weeks from first time

Table I

Comparison of $\mathrm{IgG}$ avidity maturation in serum samples obtained from seven pregnant women suspected of acute or postacute toxoplasmosis.

\begin{tabular}{|c|c|c|c|c|c|c|}
\hline \multirow{2}{*}{$\begin{array}{c}\text { Patient } \\
\text { no }\end{array}$} & \multirow{2}{*}{$\begin{array}{l}\text { Number of weeks } \\
\text { after the first } \\
\text { sample was taken }\end{array}$} & \multirow{2}{*}{$\begin{array}{l}\text { IgM (VIDAS } \\
\text { TOXO IgM) }\end{array}$} & \multicolumn{2}{|c|}{$\begin{array}{c}\text { Lysed whole cell Assay } \\
\text { (VIDAS TOXO IgG AVIDITY) }\end{array}$} & \multicolumn{2}{|c|}{ rROP1 assay } \\
\hline & & & Avidity index (AI) & Interpretation $^{b}$ & Avidity index (AI) & Interpretation $^{c}$ \\
\hline \multirow{2}{*}{1} & 0 & + & 0.106 & Low & 0.19 & Low \\
\hline & 24 & + & 0.117 & Low & 0.24 & Low \\
\hline \multirow{2}{*}{2} & 0 & + & 0.03 & Low & 0.27 & Low \\
\hline & 3 & + & 0.044 & Low & 0.37 & Borderline \\
\hline \multirow{2}{*}{3} & 0 & + & 0.231 & Borderline & 0.66 & High \\
\hline & 2 & + & 0.238 & Borderline & - & - \\
\hline \multirow{3}{*}{4} & 0 & - & 0.121 & Low & 0.35 & Borderline \\
\hline & 8 & - & 0.114 & Low & - & - \\
\hline & 10 & - & 0.178 & Low & - & - \\
\hline \multirow{4}{*}{5} & 0 & + & 0.108 & Low & 0.18 & Low \\
\hline & 8 & + & 0.110 & Low & 0.22 & Low \\
\hline & 12 & - & 0.111 & Low & 0.25 & Low \\
\hline & 16 & - & 0.125 & Low & - & - \\
\hline \multirow{2}{*}{6} & 0 & + & 0.217 & Borderline & 0.28 & Low \\
\hline & 8 & + & 0.257 & Borderline & 0.31 & Borderline \\
\hline \multirow{2}{*}{7} & 0 & + & 0.103 & Low & 0.22 & Low \\
\hline & 4 & + & 0.12 & Low & 0.23 & Low \\
\hline
\end{tabular}

${ }^{a}+$ means that patient has IgM, - means absence of IgM.

${ }^{b}$ AI below 0.2 means low avidity index, $0.2-0.3$ - borderline avidity index, over 0.3 - high avidity index,

${ }^{c}$ AI below 0.3 means low avidity index, $0.3-0.4$ - borderline avidity index, over 0.4 - high avidity index, - means lack of r-ROP1 antigen reactivity with $\mathrm{IgG}$ specific antibodies. 


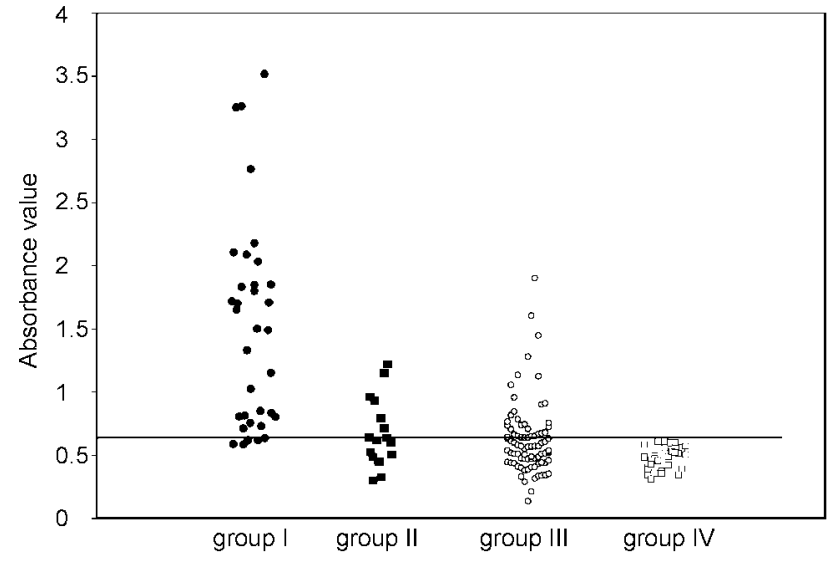

Fig. 1. Immunoreactivity of r-ROP1 protein with four groups of sera (diluted 1:100) from patients with acute $(\bullet)$, postacute $(\boldsymbol{\square})$, and chronic phase of toxoplasmosis $(\mathrm{O})$ and from seronegative individuals $(\square)$.

Absorbance was measured at $492 \mathrm{~nm}$. Horizontal line represents the cutoff value $(0.642)$.

of serum delivery. These results together with those obtained for group III sera, where specific antibodies against $\mathrm{r}$-ROP1 were not detected in $75 \%$ of serum samples from patients with chronic toxoplasmosis, confirmed our previously published data (HolecGąsior et al., 2009) and Aubert et al. (2000) that IgG antibodies against r-ROP1 antigen are produced during the acute stage of toxoplasmosis but are uncommon in the chronic phase of the infection.

In conclusion, when specific IgG antibodies react with r-ROP1 both phases of toxoplasmosis can be suspected. Therefore, IgG avidity assay with r-ROP1 may indicate phase of infection, where low avidity suggests acute toxoplasmosis and high avidity or lack of reactivity may indicate chronic infection. However, further work is needed before an immunoassay with recombinant ROP1 antigen will be useful for clinical purposes.

This work was supported by the Polish State Committee for Scientific Research, grant N N302 130438 to L.H-G.

\section{Literature}

Ashburn D., A.W. Joss, T.H. Pennington and D.O. Ho-Yen. 1998. Do $\operatorname{IgA}$, IgE, and $\operatorname{IgG}$ avidity tests have any value in the diagnosis of toxoplasma infection in pregnancy? J. Clin. Pathol. 51: $312-315$.

Aubert D., G.T. Maine, I. Villena, J.C. Hunt, L. Howard, M. Sheu, S. Brojanac, L.E. Chovan, S.F. Nowlan and J.M. Pinon. 2000. Recombinant antigens to detect Toxoplasma gondiispecific immunoglobulin $\mathrm{G}$ and immunoglobulin $\mathrm{M}$ in human sera by enzyme immunoassay. J. Clin. Microbiol. 38: 1144-1150.

Beghetto E., W. Buffolano, A. Spadoni, M. Del Pezzo, M. Di Cristina, O. Minenkova, E. Petersen, F. Felici and N. Gargano. 2003. Use of an immunoglobulin G avidity assay based on re-

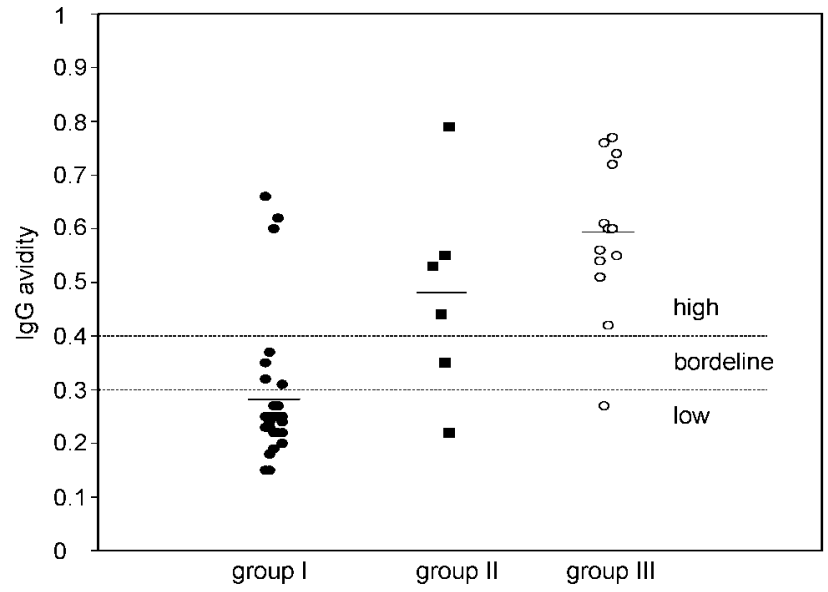

Fig. 2. IgG avidity indexes for r-ROP1 with seropositive sera from patients with an acute (O), postacute $(\boldsymbol{\square})$, and chronic toxoplasmosis $(\mathrm{O})$.

The mean value is indicated for each group by horizontal line ( 0.282 for group I; 0.480 for group II; 0.594 for group III).

combinant antigens for diagnosis of primary Toxoplasma gondii infection during pregnacy. J. Clin. Microbiol. 41: 5414-5418.

Bertozzi L.C., L.A. Suzuki and C.L. Rossi. 1999. Serological diagnosis of toxoplasmosis: usefulness of IgA detection and IgG avidity determination in patient with a persistent $\operatorname{IgM}$ antibody response to Toxoplasma gondii. Rev. Inst. Med. Trop. S. Paulo 41: 175-177.

Bessieres M.H., C. Roques, A. Berrebi, V. Barre, M. Cazaux and J.P. Seguela. 1992. IgA antibody response during acquired and congenital toxoplasmosis. J. Clin. Pathol. 45: 605-608.

Brooks R.G., R.E. McCabe and J.S. Remington. 1987. Role of serology in the diagnosis of toxoplasmic lymphadenopathy. Rev. Infect. Dis. 9: 1055-1062.

Holec-Gąsior L., J. Kur and E. Hiszczyńska-Sawicka. 2009. GRA2 and ROP1 recombinant antigen as potential markers for detection of Toxoplasma gondii - specific immunoglobulin G in humans with acute toxoplasmosis. Clin. Vaccine. Immunol. 16: $510-514$.

Iqbal J. and N. Khalid. 2007. Detection of acute Toxoplasma gondii infection in early pregnancy by IgG avidity and PCR analysis. J. Med. Microbiol. 56: 1495-1499.

Jenum P.A., B. Stray-Pedersen and A.G. Gundersen. 1997. Improved diagnosis of primary Toxoplasma gondii infection in early pregnancy by determination of antitoxoplasma immunoglobulin G avidity. J. Clin. Microbiol. 35: 1972-1977.

Lappalainen M., P. Koskela, M. Koskiniemi, P. Ammälä, V. Hiilesmaa, K. Teramo, K.O. Raivio, J.S. Remington and K. Hedman. 1993. Toxoplasmosis acquired during pregnancy: improved serodiagnosis based on avidity of IgG. J. Infect. Dis. 167: 691-697.

Liesenfeld O., J.G. Montoya, S. Kinney, C. Press and J.S. Remington. 2001. Effect of testing for IgG avidity in the diagnosis of Toxoplasma gondii infection in pregnant women: experience in a US reference laboratory. J. Infect. Dis. 183: $1248-1253$

Liesenfeld O., C. Press and J.G. Montoya. 1997. False-positive results in immunoglobulin M (IgM) Toxoplasma antibody test and importance of confirmatory testing: Platelia toxo IgM test. J. Clin. Microbiol. 35: 174-178.

Marcolino P.T., D.A.O. Silva, P.G. Leser, M.E. Camargo and J.R. Mineo. 2000. Molecular markers in acute and chronic 
phases of human toxoplasmosis: determination of immunoglobulin $\mathrm{G}$ avidity by Western Blotting. Clin. Diagn. Lab. Immunol. 7: 384-389.

McAuley J., K.M. Boyer, D. Patel, M. Mets, C. Swisher, N. Roizen, C. Wolters, L. Stein, M. Stein and W. Schey. 1994. Early and longitudinal evaluations of treated infants and children and untreated historical patients with congenital toxoplasmosis: the Chicago Collaborative Treatment Trial. Clin. Infect. Dis. 18: 38-72.

Montoya J.G., O. Liesenfeld, S. Kinney, C. Press and J.S. Remington. 2002. VIDAS test for avidity of Toxoplasma-specific immunoglobulin $\mathrm{G}$ for confirmatory testing of pregnant women. J. Clin. Microbiol. 40: 2504-2508.

Paul M. 1999. Immunoglobulin G avidity in diagnosis of toxoplasmic lymphadenopathy and ocular toxoplasmosis. Clin. Diagn. Lab. Immunol. 6: 514-518.
Pfrepper K.I., G. Enders, M. Gohl, D. Krczal, H. Hlobil, D. Wassenberg and E. Soutschek. 2005. Serorectivity to and avidity for recombinant antigens in toxoplasmosis. Clin. Diagn. Lab. Immunol. 12: 977-982.

Pietkiewicz H., E. Hiszczyńska-Sawicka, J. Kur, E. Petersen, H.V. Nielsen, M. Paul, M. Stankiewicz and P. Myjak. 2007. Usefulness of Toxoplasma gondii recombinant antigens (GRA1, GRA7, SAG1) in an immunoglobulin G avidity test for serodiagnosis of toxoplasmosis. Parasitol. Res. 100: 333-337.

Sáfadi M.A., E.N. Berezin, C.K. Farhat and E.S. Carvalho. 2003. Clinical presentation and follow up of children with congenital toxoplasmosis in Brazil. Braz. J. Infect. Dis. 7: 325-331. Villavedra M., J. Battiston and A. Nieto. 1999. IgG recognizing $21-24 \mathrm{kDa}$ and $30-33 \mathrm{kDa}$ tachyzoite antigens show maximum avidity maturation during natural and accidental human toxoplasmosis. Rev. Inst. Med. Trop. S. Paulo 41: 297-303. 